\title{
SOCIAL STABILITY RISK EVALUATION OF MAJOR WATER CONSERVANCY PROJECTS IN FRAGILE ECO-ENVIRONMENT REGIONS
}

\author{
WU, Q. ${ }^{1,2}-$ WANG, L. ${ }^{2 *}-$ JIN, N. ${ }^{3}-\mathrm{LI}, \mathrm{N}^{2}-\mathrm{HU}, \mathrm{X} .{ }^{2}$ \\ ${ }^{1}$ College of Management, Xi'an University of Architecture \& Technology \\ Yanta Rd. 13, Beilin District, Xi'an 710055, China \\ ${ }^{2}$ School of Civil Engineering, Xi'an University of Architecture \& Technology \\ Yanta Rd. 13, Beilin District, Xi'an 710055, China \\ ${ }^{3}$ Shaanxi Province Institute of Water Resource and Electric Power Investigation \& Design \\ East St. 57, Beilin District, Xi'an 710001, China \\ *Corresponding author \\ e-mail:wllucky2019@163.com \\ (Received $18^{\text {th }}$ Mar 2019; accepted $17^{\text {th }}$ May 2019)
}

\begin{abstract}
Considering the importance of social stability risk evaluation for major water conservancy projects (MWCPs), this paper creates a feasible evaluation index system for such projects in fragile ecoenvironment regions (FEER) through literature review, questionnaire surveys and data analysis. Then, a risk evaluation model was construction based on the set pair analysis (SPA) and the principal component analysis (PCA). The proposed model was applied to a MWCP in Shaanxi Province, China, revealing that the project has a low level of social stability risk. The evaluation result agrees with the actual situation, confirming the reliability and rationality of the proposed model. On this basis, several suggestions were proposed to further mitigate the social stability risks of the MWCPs in the FEER. The research findings provide a valuable reference for similar projects in FEER.
\end{abstract}

Keywords: social risk, index system, set pair analysis (SPA), suggestions, China, case study

\section{Introduction}

Water conservancy projects bring many benefits to regional and national development, such as controlling flood, protecting the eco-environment, rationalizing the use of water resources, and promoting economic development. In recent years, water conservancy projects are springing up across China, in response to the surging demand for industrial and domestic water $(\mathrm{Qu}, 2017)$. A total of RMB 713.24 billion yuan was spent on water conservancy projects in 2017, and another 100 billion was added in the following year. In Shaanxi Province alone, 172 major water conservancy projects (MWCPs) were kicked off in 2018.

The water conservancy projects that have a huge construction scale and involve numerous factors are defined as MWCPs. In China, such projects need to be approved by the central and provincial governments. Unlike the general projects, an MWCP features a long construction period, a high investment and a large demand for land resources. In addition, such projects construction is faced with various health, ecological and economic issues (Wang et al., 2015). For example, the project party needs to consider house demolition, resettlement and compensation for reservoir immigrants. If not solved properly, these problems may lead to social instability in the project area, especially in fragile eco-environment regions (FEER). 
For MWCPs, the social stability risks mainly refer to the negative social impacts of the project construction and operation on the residents in the project area. The residents may file petitions, resort to violence or take part in mass unexpected incidents, if their interests are undermined by the project. The social stability risks of MWCPs are not uncommon. Among the 527 MWCPs funded by the World Bank, only 30 has not caused social instability, and 27 has destabilized the local society. The mean yield of the 30 project stands at $18.3 \%$, while that of the 27 projects lingers at $8.6 \%$. In 2017, the Chinese government pledged to take heavy measures against major risks of MWCPs, with the aim to improve prevention mechanisms and resolve social tensions. Over the years, the management of social stability risks has become an important aspect in the evaluation of MWCPs. Therefore, it is imperative to develop a realistic index system to rationally quantify the social stability risks of MWCPs.

The contents shape the outcomes of the evaluation of social stability risks, and the countermeasures against such risks. Without proper contents, it would be impossible to achieve the goals of project investment (SGJ, 2012; Shi et al., 2015; Yang and Lv, 2017).

Some scholars argued that a complete evaluation of social stability risks in MWCPs should cover social impacts, social suitability and social risks, and tackle such factors as the stakeholders, local population, production activities, social organizations and cultural acceptability (Becker, 2001; Eskesen et al., 2004). However, Zhang et al. (2013) suggested including social impacts, economic impacts and environmental impacts into the social stability risk evaluation of MWCPs. To achieve scientific and democratic social stability risk evaluation, Liao (2018) advised to clarify the status and duties of citizens, the government and third parties in the evaluation through "confrontational debates", fully assess the public participation and opinions of project construction, identify the project impacts on poverty, gender, immigration and ethnic minorities, and monitor the various aspects (e.g. life, resettlement and social development) of the project in a timely manner. Meanwhile, the Chinese Ministry of Water Resources stipulated that the social stability risks of MWCPs should be evaluated from the perspectives of legality, rationality, feasibility and controllability. However, this provision has not been well implemented in the existing practices.

In the evaluation of social stability risks, the index system should reflect all key attributes of the target MWCP, and contain indices that are properly correlated with each other. A suitable index system is the first step in reducing the social stability risks and the early prevention of social instability.

In 1984, the World Bank requested all construction projects to include social risk evaluation in the feasibility study (Dani, 2003). Many scholars understood the social risks of construction projects as those arising from the different responses of stakeholders to specific issues and from the conflict between policymakers and the stakeholders (Hu et al., 2013). Following this train of thought, Wang and Zhang (2012) design an evaluation index system for social stability risks, which contains such indices as institutional role, behavior, stakeholder and social risk. In 2001, the former Chinese Ministry of Railways required all railway projects to assess their social stability risks from both macro and micro angles, against indices like social impacts and the degree of integration with the local environment. He et al. (2018) explore the relationship between stakeholders and risk factors and identifies the key indices of social stability risks by social network analysis.

On MWCPs, the existing studies generally set up the evaluation index system of social stability risks from the following aspects: policy, economy, society, environment, 
behavior and governance (Sun, 2011; Peng et al., 2013; Xiao et al., 2016; Zhu et al., 2016; Hu, 2016). Using engineering analysis method, Huang et al. (2013) discussed the social stability risks of MWCPs in three dimensions, namely, social risk exposure, social sensitivity, and coping capacity. Some scholars include the public perception of risk in the index system for evaluation of social stability risks (Guo, 2012; Hu and Wang, 2014; Zhu et al., 2014; Yin et al., 2018; Zhang and Zhu, 2018; Fan, 2018). Inspired by social combustion theory and social vulnerability theory, Yang (2012) and Feng et al. (2017) measured social stability risks against such four indices as conflict diffuseness, conflict severity, conflict persistence and the total amount of conflicts. Liu et al. (2016) classified the risk factors into procedural risks, cognitive risks and friction risks. Targeting MWCPs, Teng et al. (2014) set up an index system for social stability risk evaluation, including but not limited to individual, family, political structure, social structure, direct impacts, public resources, eco-environment, social adaptability, and community. Chen and Wang (2018) identified the risk factors of public-private partnership (PPP) project against the indices of the government, social capital, public and environment, and summed up the risk formation mechanism. Liu and Wang (2017), and Yu et al. (2016) probed into the evaluation index system of social stability risks in urban transit projects and major river projects, but did not come up with a unified index system.

MWCPs involve numerous influencing factors, making it difficult to use a unified evaluation method. The evaluation method should properly quantify the degree and probability of each social stability risk.

From the angle of stakeholders, Jiao et al. (2015) evaluated the social stability risks of MWCPs by the fuzzy weighting method. Song (1995) assessed the social stability risks of MWCPs using the state-response mechanism. Cao et al. (2013) carried out a questionnaire survey on engineers and social evaluation experts, asked them to rate each social stability risk, and determined the weight of each risk based on the ratings. Chen et al. (2013) adopted the analytic hierarchy process (AHP) to assess the social stability risks of MWCPs. Sturk et al. (1996) suggested that the fault tree analysis (FTA) and the hazard and operability study (HAZOP) are applicable to risk evaluation, and successfully employed the FTA to evaluate the social stability risks of an actual project. Clark and Borst (2002) relied on the risk index method to assess various risks on the underground transit line in Seattle. Based on the entropy-weight and matter-element extension model, Dong et al. (2018) proposed a social stability risk evaluation method for highway projects, which computes the classical domain and the correlation function of each index, takes the entropy as the weight of the index, calculates the comprehensive correlation and then grades the social stability risks of the project.

In summary, the following methods have been frequently adopted to evaluate the social stability risks of MWCPs: the AHP, fuzzy comprehensive evaluation (FCE), grey comprehensive evaluation, principle of Maximum Entropy (Li et al., 2009), group decision AHP (GAHP) (Kong et al., 2015), hierarchal holographic modeling (HHM), fuzzy variable theory (Xiao, 2017) and evaluation models combining various mathematical methods (He and Yang, 2014; Wu et al., 2016; Ma, 2017; Wang, 2017; Ge et al., 2018). These methods share some common defects. For example, the evaluation indices are too rigid to evaluate ambiguous, random and uncertain phenomena, the risk levels are determined rather subjectively, and the computing is so complex as to produce errors. 


\section{Materials and Methods}

\section{Evaluation index system}

\section{Preliminary selection}

As required by the Chinese Ministry of Water Resources, legality, rationality, feasibility and controllability were the contents of our evaluation of social stability risks in MWCPs. On this basis, the indices of each content were selected preliminarily, forming a hierarchy structure. Next, the preliminary evaluation index system was set up in light of the indices in actual cases, those in similar projects and the features of the target project.

\section{Index screening}

The indices are qualitative variables that measure the subjective feelings of the respondents. Here, each index was rated against a 5-point Likert scale (1: Very unimportant; 2: Unimportant; 3: Neither important nor unimportant; 4: Important; 5: Very important). Before issuing the formal questionnaire, all items were subjected to several tests (Table 1). The unqualified terms were deleted in view of the experts' opinions.

(1) Correlation test

The correlation test aims to determine the Pearson product moment coefficient, i.e. the correlation between an item's scores and the total test scores, of each item. The test results show that three indices, including decision-making power $\mathrm{u}_{11}$, institutional construction $\mathrm{u}_{12}$ and acquisition and demolition scale $\mathrm{u}_{13}$, were not significant or slightly significant $(\mathrm{p}<0.4)$. Thus, these descriptive items are not highly correlated with the scale.

The Chinese Ministry of Water Resources specified that the evaluation entity of social stability risks should be designated by the people's government in the project area or its subordinate departments, have clear management organization and relevant rules and regulations, and maintain no direct interest-relationship with the project; the social stability risk evaluation report should be signed by the people's government in the project area. Therefore, the decision-making power and institutional construction of government departments are not inducers of social stability risks.

In addition, the rationality of acquisition and demolition scale depends on the quality of planning, design and related measures. This item is not a direct cause of social risk events. To sum up, the decision-making power, institutional construction and acquisition and demolition scale were deleted from our index system.

(2) Validity test

Before the factor analysis, the remaining 21 items received the validity test. The results show that the Kaiser-Meyer-Olkin (KMO) value was 0.679, above the 0.6 threshold; the $\mathrm{p}$ value of Bartlett's test of sphericity was 0.000 , which is significant at the level of 0.05 . This means the proposed scale is suitable for factor analysis.

From the factor analysis, the minimum common value $\mathrm{u}_{43}$ was determined as 0.510 , and all items were above 0.2 , indicating that the factor acceptable. Besides, the factor load was greater than 0.5 and the cumulative contribution rate of the four factors reached $70.189 \%$, above the required rate of $70 \%$. Therefore, the 21 items can be retained for subsequent analysis and the scale is of good validity.

(3) Reliability test

The Cronbach's alpha of the total scale (0.931) was greater than 0.9 , signifying the good overall reliability of the scale. Generally, when the total correlation of the 
correction item is below 0.4, an item should be deleted if the Cronbach's alpha after deletion is greater than or equal to that of the total scale. Among the 21 items, the resettlement plan $\mathrm{u}_{29}$ had a Cronbach's alpha lower than 0.4, and the Cronbach's alpha after deleting this item equaled that of the total scale. After consulting experts, it is confirmed that this term is a trigger of mass unexpected incidents in similar projects, and thus not deleted. The other items all passed the reliability test. The Cronbach's alphas of the subscales also passed the test, indicating that the scale reliability will not increase after removal of any item. As a result, all 21 items can be retained for subsequent analysis and the scale is of high reliability.

Table 1. The results of the reliability test $(\mathrm{Wu}, 2010)$

\begin{tabular}{|c|c|c|c|c|c|c|c|c|}
\hline \multirow{2}{*}{ Item } & \multicolumn{2}{|c|}{$\begin{array}{l}\text { Correlation coefficient } \\
\text { between the item and the } \\
\text { total score }\end{array}$} & \multicolumn{5}{|c|}{ Homogeneity test } & \multirow{2}{*}{ Remarks } \\
\hline & $\begin{array}{c}\text { Pearson } \\
\text { Correlation }\end{array}$ & $\begin{array}{l}\text { Significant } \\
\text { (bilateral) }\end{array}$ & $\begin{array}{l}\text { Corrected } \\
\text { item total } \\
\text { relevance }\end{array}$ & $\begin{array}{l}\text { alpha value } \\
\text { after the item } \\
\text { is deleted }\end{array}$ & $\begin{array}{c}\text { Subscale } \\
\text { alpha value }\end{array}$ & $\begin{array}{c}\text { Commo- } \\
\text { nality }\end{array}$ & $\begin{array}{c}\text { Factor } \\
\text { load }\end{array}$ & \\
\hline $\mathrm{u}_{11}$ & 0.044 & 0.807 & & & & & & Deleted \\
\hline $\mathrm{u}_{12}$ & 0.34 & 0.053 & & & & & & Deleted \\
\hline $\mathrm{u}_{13}$ & 0.582 & 0 & 0.498 & 0.927 & 0.717 & 0.742 & 0.779 & Reserved \\
\hline $\mathrm{u}_{14}$ & 0.455 & 0.008 & 0.4 & 0.93 & & 0.51 & 0.517 & Reserved \\
\hline $\mathrm{u}_{15}$ & 0.774 & 0 & 0.726 & 0.924 & & 0.89 & 0.783 & Reserved \\
\hline $\mathrm{u}_{21}$ & 0.678 & 0 & 0.677 & 0.924 & & 0.689 & 0.722 & Reserved \\
\hline $\mathrm{u}_{22}$ & 0.723 & 0 & 0.719 & 0.923 & & 0.8 & 0.659 & Reserved \\
\hline $\mathrm{u}_{23}$ & 0.822 & 0 & 0.812 & 0.922 & & 0.805 & 0.629 & Reserved \\
\hline $\mathrm{u}_{24}$ & 0.757 & 0 & 0.71 & 0.923 & & 0.729 & 0.545 & Reserved \\
\hline $\mathrm{u}_{25}$ & 0.745 & 0 & 0.761 & 0.922 & 0.875 & 0.799 & 0.777 & Reserved \\
\hline $\mathrm{u}_{26}$ & 0.448 & 0.009 & 0.403 & 0.929 & & 0.781 & 0.802 & Reserved \\
\hline $\mathrm{u}_{27}$ & 0.679 & 0 & 0.646 & 0.925 & & 0.659 & 0.729 & Reserved \\
\hline $\mathrm{u}_{28}$ & 0.733 & 0 & 0.687 & 0.924 & & 0.698 & 0.701 & Reserved \\
\hline $\mathrm{u}_{29}$ & 0.408 & 0.019 & 0.325 & 0.931 & & 0.827 & 0.882 & Reserved \\
\hline $\mathrm{u}_{31}$ & 0.551 & 0.001 & 0.477 & 0.928 & & 0.694 & 0.749 & Reserved \\
\hline $\mathrm{u}_{32}$ & 0.659 & 0 & 0.613 & 0.925 & & 0.68 & 0.688 & Reserved \\
\hline $\mathrm{u}_{33}$ & 0.486 & 0.004 & 0.381 & 0.93 & 0.717 & 0.526 & 0.622 & Reserved \\
\hline $\mathrm{u}_{34}$ & 0.349 & 0.046 & & & & & & Deleted \\
\hline $\mathrm{u}_{35}$ & 0.813 & 0 & 0.78 & 0.923 & & 0.68 & 0.582 & Reserved \\
\hline $\mathrm{u}_{41}$ & 0.682 & 0 & 0.651 & 0.925 & & 0.813 & 0.681 & Reserved \\
\hline $\mathrm{u}_{42}$ & 0.664 & 0 & 0.668 & 0.925 & & 0.639 & 0.579 & Reserved \\
\hline $\mathrm{u}_{43}$ & 0.516 & 0.002 & 0.493 & 0.928 & 0.815 & 0.449 & 0.587 & Reserved \\
\hline $\mathrm{u}_{44}$ & 0.649 & 0 & 0.574 & 0.926 & & 0.696 & 0.787 & Reserved \\
\hline $\mathrm{u}_{45}$ & 0.652 & 0 & 0.646 & 0.925 & & 0.634 & 0.737 & Reserved \\
\hline $\begin{array}{l}\text { Discrimi- } \\
\text { nant } \\
\text { criterion }\end{array}$ & $\geq 0.400$ & $\mathrm{p}<0.05$ & $\geq 0.400$ & $\begin{array}{l}\text { <aggregate } \\
\text { alpha } \\
\text { coefficient } \\
0.931\end{array}$ & $\geq 0.7$ & $\geq 0.2$ & $\geq 0.5$ & \\
\hline
\end{tabular}

\section{Construction of index system}

The expression of the indices was further refined and renumbered, forming a reliable and valid index system containing 21 indices (Table 2). 
Table 2. The evaluation index system for social stability risks of MWCPs

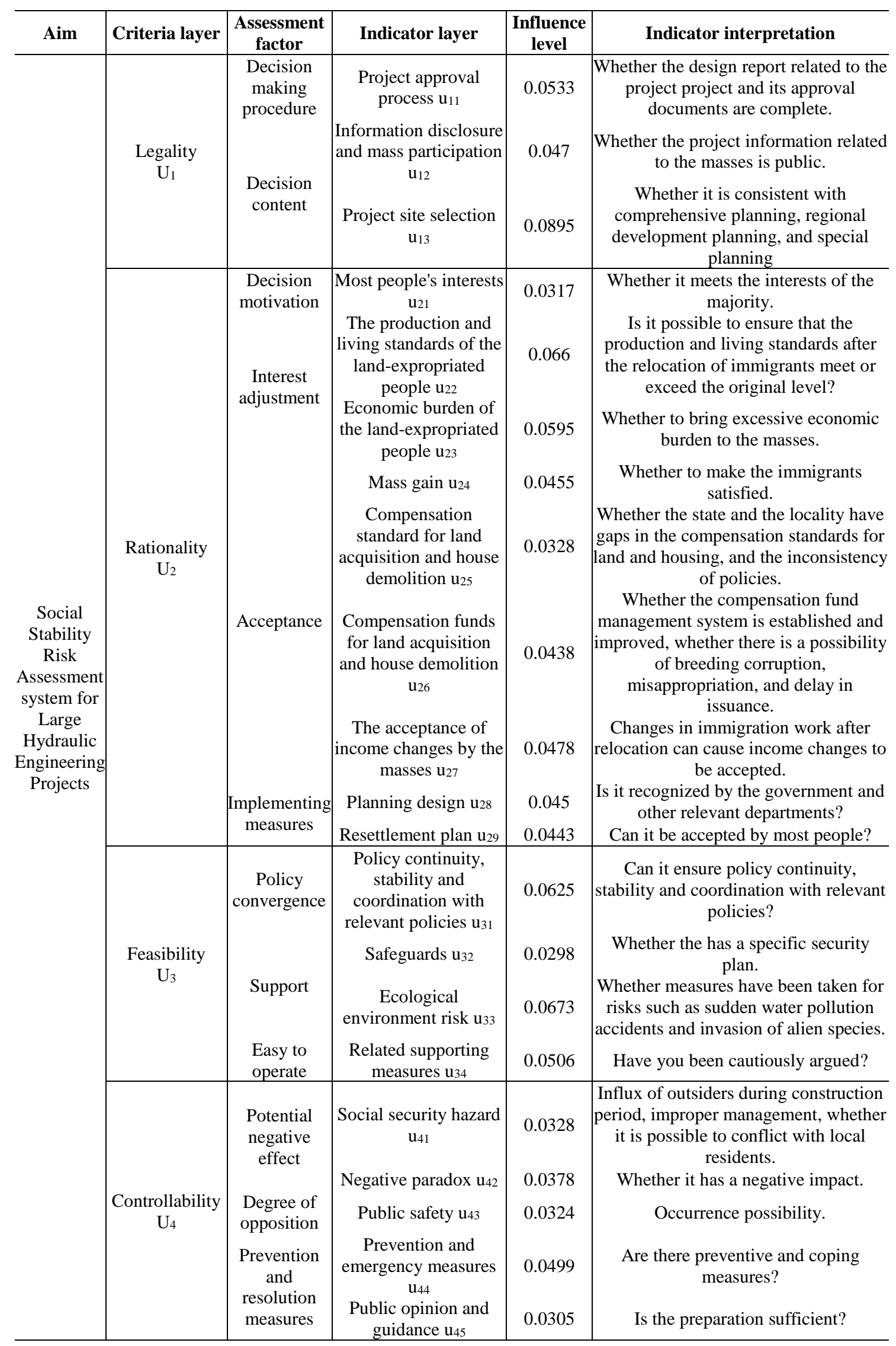




\section{Evaluation Model}

Set pair analysis (SPA)

The SPA (Zhao, 2000) is an effective way to quantify random, ambiguous and uncertain problems. It enjoys great advantages in quantifying the uncertainty between multiple factors. Taking the target problem as a system, the certain features are considered as the same or opposite to each other, the uncertain features are deemed as different, and the target system is analyzed from the same, different, and opposite aspects. The set pair is a pair of two sets with a certain correlation.

Let $\mathrm{H}=(\mathrm{X}, \mathrm{Y})$ be a pair set, and $\mathrm{N}$ be the total number of features in the set. It is assumed that the set contains $\mathrm{S}$ same features, $\mathrm{P}$ opposite features and $\mathrm{F}$ different features, that is, $\mathrm{N}=\mathrm{S}+\mathrm{F}+\mathrm{P}$. Then, the correlation degree of the system can be described as (Wang et al., 2009; Yang et al., 2014):

$$
\mu=\mathbf{a}+b i+c j=\frac{S}{N}+\frac{F}{N} i+\frac{P}{N} j
$$

where $i \in[-1,1]$ is the difference coefficient for uncertain features; $j=-1$ is the oppositeness coefficient for certain features. The key to the SPA lies in the determination of the correlation degree $\mu$ and the difference coefficient $i$.

\section{Evaluation model}

(1) Grading of risk probability

The risk probability refers to the possibility of occurrence of the risk index. In this paper, the subjective probability estimation is employed, which infers the risk probability based on estimators, expert experience, and similar events. The risk probability was empirically divided into five levels: very high, high, medium, low and very low. The five qualitative levels were respectively converted into quantitative figures like zero, the three quartering points of $[0,1]$ and one (Table 3$)$.

Table 3. Risk probability criterion

\begin{tabular}{c|c|c}
\hline Risk level & $\begin{array}{c}\text { Quantitative } \\
\text { standard }\end{array}$ & Level description \\
\hline Very high $(\mathrm{k}=1)$ & $(0.8,1]$ & Almost certain \\
Higher $(\mathrm{K}=2)$ & $(0.6,0.8]$ & Very likely to happen \\
Medium $(\mathrm{K}=3)$ & $(0.4,0.6]$ & May happen \\
Lower $(\mathrm{K}=4)$ & $(0.2,0.4]$ & Less likely to occur \\
Very low $(\mathrm{K}=5)$ & {$[0,0.2]$} & The possibility of occurrence is small, almost impossible \\
\hline
\end{tabular}

(2) Determination of correlation degree

The correlation degree quantifies the proximity of the two sets in the set pair, and reveals the complex relationship between the two sets. Inspired by the SPA theory, the correlation degree $\mu_{\mathrm{nk}}$ was constructed between the value $\mathrm{xn}$ of each index in the index system and the five risk probability levels $\mathrm{k}$. The relationship between each index and each level can be calculated as (Li et al., 2019): 


$$
\begin{gathered}
\mu_{\mathrm{n} 1}=\left\{\begin{array}{cc}
1 & s_{0} \leq x_{n} \triangleleft s_{1} \\
1-2 \frac{x_{n}-s_{1}}{s_{2}-s_{1}} & s_{1} \leq x_{n} \triangleleft s_{2} \\
-1 & x_{n} \geq s_{2}
\end{array}\right. \\
\mu_{\mathrm{n} 2}=\left\{\begin{array}{cc}
1-2 \frac{s_{1}-x_{n}}{s_{1}-s_{0}} & s_{0} \leq x_{n} \triangleleft s_{1} \\
1 & s_{1} \leq x_{n} \triangleleft s_{2} \\
1-2 \frac{x_{n}-s_{1}}{s_{2}-s_{1}} & s_{2} \leq x_{n} \triangleleft s_{3} \\
-1 & x_{n} \geq s_{3}
\end{array}\right. \\
\mu_{\mathrm{n} 3}=\left\{\begin{array}{cc}
\mu_{\mathrm{n} 5}=\left\{\begin{array}{cl}
1 & s_{0} \leq x_{n} \triangleleft s_{1} \\
-1 & s_{2}-x_{n} \\
s_{2}-s_{1} & s_{1} \leq x_{n} \triangleleft s_{2} \\
1 & s_{2} \leq x_{n} \triangleleft s_{3} \\
1-2 \frac{x_{n}-s_{3}}{s_{4}-s_{3}} & s_{3} \leq x_{n} \triangleleft s_{4} \\
-1 & s_{4} \leq x_{n} \triangleleft s_{5}
\end{array}\right. \\
1-2 \frac{x_{n}-s_{4}}{s_{5}-s_{4}} & s_{4} \leq x_{n} \triangleleft s_{5} \\
-1 & s_{n} \triangleleft s_{5} \\
1-2 \frac{s_{3}-x_{n}}{s_{1}-s_{0}} & s_{2} \leq x_{n} \triangleleft s_{3} \\
1 & x_{3} \triangleleft s_{3}
\end{array}\right.
\end{gathered}
$$

where $\mathrm{s}_{0} \sim \mathrm{S}_{5}$ are the critical values of the indices.

(3) Determination of degree of impact

The degree of impact of each risk index was assessed by the synthetic evaluation based on the principal component analysis (PCA). The PCA mainly determines the degree of impact based on expert scores and simplified linear relationships (Han et al., 2012). The PCA-based synthetic evaluation is implemented in four steps:

Step 1: Normalize the sample matrix $X=\left(x_{\mathrm{ij}}\right)_{n \times p}$ into $Z$, and compute the correlation coefficient matrix $R$.

Step 2: Calculate the eigenvalue $\lambda_{k}$ of the correlation matrix $\mathrm{R}$, and determine the number $(\mathrm{m})$ of principal components $\mathrm{F}_{\mathrm{j}}$. Here, more than $85 \%$ of the principal components are selected, and the remaining components are neglected.

Step 3: Determine the degree of impact of each risk index using the following model:

$$
F_{\mathrm{j}}=u_{1 j} \omega_{1}+u_{2 j} \omega_{2}+\cdots u_{n j} \omega_{n}
$$

where $u_{i j}=\frac{f_{i j}}{\sqrt{\lambda_{j}}}$ is decision matrix coefficient; $f_{i j}$ is the initial factor load. 
Step 4: Construct a comprehensive evaluation function $F_{z}$; obtain the comprehensive value of the risk index score from the expert score $x_{i \bar{i}}$ :

$$
V_{\mathrm{zi}}=\sum_{j=1}^{n} a_{j} x_{i j}
$$

The degree of impact of each risk factor:

$$
\omega_{i}=\frac{V_{Z i}}{\sum_{i=1}^{h} V_{Z i}}
$$

In this way, the model on the degree of impact of each risk index can be obtained as:

$$
F_{\mathrm{z}}=\sum_{j=1}^{m}\left(\lambda_{j} / k\right) F_{\mathrm{j}}=a_{1 m} \omega_{1}+a_{2 m} \omega_{2}+\ldots a_{n m} \omega_{n}
$$

where $a_{1}, \cdots, a_{n}$ are the overall importance of indices in the principal component.

Using the SPSS 20.0 and the above method, the initial degree of impact of each index can be computed as:

$$
\left\{\begin{array}{l}
F_{1}=0.1080 \omega_{1}+0.0866 \omega_{2}+\ldots+0.1322 \omega_{21} \\
F_{2}=-0.0064 \omega_{1}-0.0321 \omega_{2}+\ldots-0.0106 \omega_{21} \\
\cdots \\
F_{5}=-0.0228 \omega_{1}+0.0298 \omega_{2}+\ldots-0.0069 \omega_{21}
\end{array}\right.
$$

The secondary model was obtained from the above results and the expert score sheet as: $F_{z}=0.1335 \omega_{1}+0.1259 \omega_{2}+\ldots+0.0905 \omega_{21}$. The degree of impact of each of 21 risk indices was $\omega=\left(\omega_{1}, \omega_{1}, \ldots, \omega_{21}\right)=(0.0533,0.0470, \ldots, 0.0305)$.

(4) Calculation of comprehensive correlation

The comprehensive correlation between index $\mathrm{n}$ and the risk probability level $\mathrm{k}$ can be determined as:

$$
V_{i k}=\sum_{i=1}^{n} \omega_{i} \mu_{i k}
$$

(5) Determining the evaluation scores

According to the basic principle of the SPA, the score of the risk probability is the level corresponding to the maximum value of the comprehensive correlation:

$$
U=\operatorname{Max}_{j=1}^{k}\left\{v_{i k}\right\}
$$

\section{Results}

\section{Basic information}

The research target is an MWCP in the FEER of northwestern China's Shaanxi Province. With a total investment of RMB 20 billion yuan, the project covers an area of 
$14,00 \mathrm{~km}^{2}$. To prevent the occurrence of mass unexpected incidents, the author carried out an evaluation of the social stability risks of the project.

Prior to the evaluation, a questionnaire survey was carried out in 35 administrative villages of 10 districts and counties. The questionnaire covers the attitude to the project, the impacts on local environment, the impacts on production and life, the compensation for losses, public participation, and so on. In total, 1,200 questionnaires were released, $86 \%$ of which were recovered. Meanwhile, a few questionnaires were issued to test the authenticity, credibility and perfection of the survey. The results indicate that the survey contents lay a solid basis for risk evaluation.

The questionnaire data show that 1,028 villagers were not against the project, including 951 supporters, 77 unconcerned and 3 opponents. The support rate is as high as $99.7 \%$. Only 57 villagers worried about the risk of social instability, while 974 did not have the worry. Most villagers learned about the project from a simple information source. Specifically, 992 villagers heard of the project from the bulletin board of the local cooperative, and 8 never heard of the project. In addition, 10 villagers were included in the resettlement plan. Most respondents $(1,124)$ were concerned about the compensation standards for land acquisition and house demolition, such as the compensation time. In general, land acquisition, relocation and resettlement and the temporary shutdown of the irrigation facilities are the main aspects of the project that may affect the local production and life. Besides, conflicts may arise between the construction team and the villagers.

According to the actual situation of the project area, a social stability risk evaluation report was prepared, and several risk mitigation measures were proposed, together with an emergency response plan.

\section{Risk evaluation}

Based on the survey data, the social risks of the project were evaluated by the proposed method. The expert scores on each index was averaged as the final score (Table 4). The correlation degrees of each index and the evaluation levels were computed by Equations (2) and (6) (Table 5).

Table 4. Mean expert score on each index

\begin{tabular}{c|c|c|c|c|c|c|c}
\hline Index & $\begin{array}{c}\text { Experts rating } \\
\text { average }\end{array}$ & $\begin{array}{c}\text { Own } \\
\text { interval }\end{array}$ & $\begin{array}{c}\text { Risk } \\
\text { level }\end{array}$ & Index & $\begin{array}{c}\text { Experts rating } \\
\text { average }\end{array}$ & $\begin{array}{c}\text { Own } \\
\text { interval }\end{array}$ & $\begin{array}{c}\text { Risk } \\
\text { level }\end{array}$ \\
\hline $\mathrm{u}_{11}$ & 0.76 & $(0.6,0.8]$ & Higher & $\mathrm{u}_{29}$ & 0.44 & $(0.4,0.6]$ & Medium \\
$\mathrm{u}_{12}$ & 0.6 & $(0.4,0.6]$ & Medium & $\mathrm{u}_{31}$ & 0.5 & $(0.4,0.6]$ & Medium \\
$\mathrm{u}_{13}$ & 0.7 & $(0.6,0.8]$ & Higher & $\mathrm{u}_{32}$ & 0.56 & $(0.4,0.6]$ & Medium \\
$\mathrm{u}_{21}$ & 0.72 & $(0.6,0.8]$ & Higher & $\mathrm{u}_{25}$ & 0.46 & $(0.4,0.6]$ & Medium \\
$\mathrm{u}_{22}$ & 0.6 & $(0.4,0.6]$ & Medium & $\mathrm{u}_{26}$ & 0.6 & $(0.4,0.6]$ & Medium \\
$\mathrm{u}_{23}$ & 0.8 & $(0.6,0.8]$ & Higher & $\mathrm{u}_{27}$ & 0.84 & $(0.6,0.8]$ & Higher \\
$\mathrm{u}_{24}$ & 0.62 & $(0.6,0.8]$ & Higher & $\mathrm{u}_{28}$ & 0.7 & $(0.6,0.8]$ & Higher \\
$\mathrm{u}_{25}$ & 0.62 & $(0.6,0.8]$ & Higher & $\mathrm{u}_{29}$ & 0.6 & $(0.4,0.6]$ & Medium \\
$\mathrm{u}_{26}$ & 0.66 & $(0.6,0.8]$ & Higher & $\mathrm{u}_{31}$ & 0.72 & $(0.6,0.8]$ & Higher \\
$\mathrm{u}_{27}$ & 0.6 & $(0.4,0.6]$ & Medium & $\mathrm{u}_{32}$ & 0.8 & $(0.6,0.8]$ & Higher \\
$\mathrm{u}_{28}$ & 0.6 & $(0.4,0.6]$ & Medium & & & & \\
\hline
\end{tabular}


Table 5. The correlation degrees of each index and the evaluation levels

\begin{tabular}{|c|c|c|c|c|c|c|c|c|c|c|c|}
\hline \multirow{3}{*}{ Index } & \multicolumn{5}{|c|}{$\begin{array}{c}\text { Degree of contact for different evaluation } \\
\text { levels }\end{array}$} & \multirow{3}{*}{ Index } & \multicolumn{5}{|c|}{$\begin{array}{c}\begin{array}{c}\text { Degree of contact for different evaluation } \\
\text { levels }\end{array} \\
\end{array}$} \\
\hline & $\begin{array}{l}\text { Very } \\
\text { high }\end{array}$ & Higher & Medium & Lower & $\begin{array}{l}\text { Very } \\
\text { low }\end{array}$ & & $\begin{array}{l}\text { Very } \\
\text { high }\end{array}$ & Higher & Medium & Lower & $\begin{array}{l}\text { Very } \\
\text { low }\end{array}$ \\
\hline & $(\mathbf{0 . 8 , 1 ]}$ & $(0.6,0.8]$ & $(\mathbf{0 . 4 , 0 . 6}$ & $(0.2,0.4]$ & {$[0,0.2]$} & & $(\mathbf{0 . 8}, 1]$ & $(0.6,0.8$ & $(\mathbf{0 . 4 , 0 . 6 ]}$ & $(0.2,0.4]$ & {$[0,0.2]$} \\
\hline $\mathrm{u}_{11}$ & -1 & -1 & -0.6 & 1 & 0.8 & $\mathrm{u}_{29}$ & -1 & 0.6 & 1 & -0.6 & -1 \\
\hline $\mathrm{u}_{12}$ & -1 & -1 & 1 & 1 & -1 & $\mathrm{u}_{31}$ & -1 & -1 & 1 & 0 & -1 \\
\hline $\mathrm{u}_{13}$ & -1 & -1 & 0 & 1 & 0 & $\mathrm{u}_{32}$ & -1 & -0.6 & 1 & 0.6 & -1 \\
\hline $\mathrm{u}_{21}$ & -1 & -1 & -0.2 & 1 & 0.2 & $\mathrm{u}_{33}$ & -1 & 0.4 & 1 & -0.4 & -1 \\
\hline $\mathrm{u}_{22}$ & -1 & -1 & 1 & 1 & -1 & $\mathrm{u}_{34}$ & -1 & -1 & 1 & 1 & -1 \\
\hline $\mathrm{u}_{23}$ & -1 & -1 & -1 & 1 & 1 & $\mathrm{u}_{41}$ & -1 & -1 & -1 & 0.6 & 1 \\
\hline $\mathrm{u}_{24}$ & -1 & -1 & 0.8 & 1 & -0.8 & $\mathrm{u}_{42}$ & -1 & -1 & 0 & 1 & 0 \\
\hline $\mathrm{u}_{25}$ & -1 & -1 & 0.8 & 1 & -0.8 & $\mathrm{u}_{43}$ & -1 & -1 & 1 & 1 & -1 \\
\hline $\mathrm{u}_{26}$ & -1 & -1 & 0.4 & 1 & 0.3 & $\mathrm{u}_{44}$ & -1 & -1 & -0.2 & 1 & 0.2 \\
\hline $\mathrm{u}_{27}$ & -1 & -1 & 1 & 1 & -1 & $\mathrm{u}_{45}$ & -1 & -1 & -1 & 1 & 1 \\
\hline $\mathrm{u}_{28}$ & -1 & -1 & 1 & 1 & -1 & & & & & & \\
\hline
\end{tabular}

Based on the correlation degrees of each index and the evaluation levels, the weight of each index was determined according to Equation (11). The comprehensive correlation degree of each index can be calculated as:

$$
\mathrm{v}=(-0.9998,-0.82278,0.40176,0.74716,-0.36044)^{\mathrm{T}}
$$

By Equation (12), the maximum connection degree was obtained as 0.74716 , and the corresponding interval of evaluation level was $(0.2,0.4)$. The results show that the social stability risk of the major water conservancy project in the fragile ecoenvironment region is lower than the actual situation after implementing the mitigation measures. This is consistent with the actual situation.

\section{Discussion}

The existing studies on MWCPs evaluation mainly concentrate on economic benefits and environmental impacts, failing to tackle the social stability risks. What is worse, there is a severe lacking of the social stability risk evaluation of the MWCPs in the FEER, which is essential to the protection of project safety and sustainability.

To make up for this gap, this paper creates a feasible evaluation index system for social stability risks of the MWCPs in FEER through literature review, questionnaire survey and data analysis. Then, a risk evaluation model was construction based on the SPA and PCA. The proposed model was applied to a MWCP in Shaanxi Province, China, revealing that the project has a low level of social stability risk. The evaluation result agrees with the actual situation, confirming the reliability and rationality of the proposed model.

The research findings provide a valuable reference for similar projects in FEER. The risk evaluation provides a reference for the design of measures to reduce the risk of the project. Based on the actual situation of the study area and the existing studies, the author puts forward several suggestions on social risk mitigation to further mitigate the social stability risks of the WMCPs in the FEER.

(1) Address the concerns and protect the vital interests of the locals. 
The compensation policies and resettlement measures should be publicized in the project area. To formulate a feasible compensation plan, the construction team must fully understand the local conditions, solicitate the opinions of the affected, and obey the relevant regulations. Moreover, the resettlement site and supporting facilities should be selected rationally and developed rapidly. The local governments need to step up the resolution of disputes over compensation allocation and pay the compensation in time.

(2) Enhance eco-environment protection and reduce the environmental impact.

The project party must strictly abide by regulations on environmental protection, adopt practical engineering and biological measures, and strengthen environmental monitoring and management. The construction plan should be optimized to prevent water pollution, curb ecological deterioration, and avoid geological disasters. Ultimately, the negative environmental impact should be reduced to the acceptable level.

(3) Improve safety awareness and strengthen risk monitoring and response.

The project safety should be prioritized through project construction and operation. During the construction, the project party should actively learn from best practices and achieve civilized construction, the local government should implement strict supervision, and the villagers should engage in safety monitoring and report. After the project enters operation, the risk monitoring should be implemented consistently through site visits, field surveys and regular patrols.

(4) Establish and improve the risk management linkage mechanism for social stability.

The project party should establish and improve a robust mechanism of social stability and work safety. For example, the construction procedures should be followed strictly, and the applications for pre-approval be filed timely; effective working forms and response plans should be formulated as per the project features and requirements; the social risk sources should be avoided throughout the project. In addition, efforts should be paid to enhance the awareness of risk, emergency, conflict and crisis management.

(5) Cooperate with the local government to coordinate and solve problems.

The project party should actively cooperate with the local government in problem coordination and solution. Specifically, the party needs to maintain an effective communication channel with the locals, and share the information smoothly with the local government. In the event of social stability risks, the project party and the local government should work together to prevent and resolve such risks.

(6) Actively explore new measures to prevent and resolve social stability risks.

The relevant parties need to further investigates the issues on social stability risks, and actively explore new measures to prevent and eliminate such risks. The new measures should be prepared based on the opinions and problems raised by the most affected residents and the local government, with the aim to nip the problems in the bud.

\section{Conclusions}

The social stability risks are highly dynamic, and the interaction between risk factors may trigger new risk factors in unsteady areas. Due to the geographical and project characteristics, there are some limitations in the selection of evaluation indicators. It can further adjust and improve the indicator system according to the actual needs of the project. Although the target project has a low social stability risk, the occurrence of individual conflicts cannot be ruled out. This calls for a more detailed risk mitigation strategy, which will be discussed in future research. 
Acknowledgements. This work is supported by the National Natural Science Foundation of China (grant no. 51678479), the Shaanxi Provincial Science and Technology Department Natural Science Basic Research Plan (grant no. 2018JM5129), and the Shaanxi Provincial Department of Education special scientific research project (grant no. 18JK0417).

\section{REFERENCES}

[1] Becker, H. A. (2001): Social impact assessment. - European Journal of Operational Research 128(2): 311-321.

[2] Cao, F., Shao, D. K., Wang, Z. S. (2013): Social Stability Risk Assessment and Social Support Analysis of Major Engineering Projects-A Questionnaire Survey Based on a Major Natural Gas Pipeline Project. - Journal of Chinese Academy of Governance (6): 91-95.

[3] Chen, X. Z., Hu, X. M. (2013): A Study on Social Risk Assessment of Major Projects: from the Perspective of Social Expectation. - Journal of Beijing University of Aeronautics and Astronautics (Social Sciences Edition) 26(2): 15-18.

[4] Chen, Z. D., Wang, Y. (2018): Fault Tree Analysis of Social Risk of PPP Projects. Journal of Engineering Studies 10(02): 159-167.

[5] Clark, G. T., Borst, A. (2002): Addressing risk in Seattle's underground. - PB Network (1): 34-37.

[6] Dani, A. A. (2003): Social analysis sourcebook: incorporating social dimensions into bank-supported projects.

[7] Dong, Z., Wang, H., Dong, X. L. (2018): Evaluation Method for Highway Project Social Stability Risk Based on Entropy Weight Extension Matter-element Model. - China Journal of Highway and Transport 31(09): 191-198.

[8] Eskesen, S. D., Tengborg, P., Kampmann, J., Veicherts, T. H. (2004): Guidelines for tunnelling risk management: international tunnelling association, working group no. 2. Tunnelling \& Underground Space Technology 19(3): 217-237.

[9] Fan, X. (2018): Review of Social Stability Risk Assessment System for Large Construction Projects. - Journal of Engineering Studies 10(1): 98-106.

[10] Feng, Z. Z., Zhang, Y. (2017): The causes and classification of social stability risk of large projects. - Adm. Forum 1: 97-101.

[11] Ge, W., Li, Z. K., Li, J. J. (2018): Improved Set Pair Analysis and its application to Social Impact Assessment of Dam-break. - Journal of Yangtze River Scientific Research Institute: 1-7.

[12] Guo, X. (2012): The Management and Control on the Social Stability Risk of the Major Project. - Chongqing Social Sciences (7): 14-18.

[13] Han, X. H., Zhang, Y. H., Sun, F. J. (2012): The method of determining index weights based on the principal component analysis. - Journal of Ordnance Equipment Engineering 33(10): 124-126.

[14] He, G. M., Yang, Y. (2014): Social Stability Risk Assessment of Jianli-Jiangling Highway Project - Based on Fuzzy Analytic Hierarchy Process. - Applied Mechanics \& Materials 584-586: 2193-2198.

[15] He, Z., Huang, D. C., Zhang, C. Z., Fang, J. (2018): Toward a Stakeholder Perspective on Social Stability Risk of Large Hydraulic Engineering Projects in China: A Social Network Analysis. - Sustainability 10(4): 1223.

[16] Hu, Y., Chan, A. P. C., Le, Y., Jin, R. (2013): From construction megaproject management to complex project management: bibliographic analysis. - Journal of Management in Engineering 31(4): 04014052.

[17] Hu, X., Wang, F. (2014): A New Social Stability Risk Assessment Analysis Framework: Risk Perception Perspective. - Chinese Public Administration (4): 102-108. 
[18] Hu, X. M. (2016): Social Stability Risk Events of Sensitive Project—Process Model and Participat Action Logic. - China Natl. School Adm 2: 58-62.

[19] Huang, D., Zhang, C., Upmanu, L., Xu, M. (2013): Study on the Social Stability Risk of Large Hydraulic Project. - China Population Resources and Environment 23(04): 89-95.

[20] Jiao, X. P., Guo, X. P., Li, A. P. (2015): Study on social stability risk assessment of largescale engineering projects -- from the perspective of stakeholders. - Chinese Engineering Consulting (8): 28-30.

[21] Kong, Y., Gao, S., Wu, X. (2015): Social Stability Risk Assessment of Seawall Construction Project Based on Group Analytic Hierarchy Process. - Journal of China Three Gorges University (Natural Sciences) 37(5): 30-33.

[22] Li, A. H., Liu, H., Geng, L. H., (2009): Review of risk analysis of hydraulic engineering system. - Advances in Water Science 20(3): 453-459.

[23] Li, Z. K., Li, W., Ge, W. (2019): Dam Breach Environmental Impact Evaluation Based on Set Pair Analysis-Variable Fuzzy Set Coupling Model. - Journal of Tianjin University (Science and Technology) 52(3): 269-276.

[24] Liao, X. (2018): The Construction of A Risk Assessment Model for the "Confrontation Style" of Large Administrative Decision-making. - Journal of Chinese Public Administration 1: 58-63.

[25] Liu, Z., Zhu, Z., Wang, H. (2016): Handling social risks in government-driven mega project: An empirical case study from West China. - International Journal of Project Management 34(2): 202-218.

[26] Liu, X. H., Wang, Z. N. (2017): Urban Rail Transit Social Stability Risk Assessment. Construction Technology 46(S2): 1480-1482.

[27] Ma, C. G. (2017): The research on risk assessment of social stability of hydraulic engineering based on FAHP and entropy weight. - North China University of Water Resource and Electric Power.

[28] Peng, Z., Cao, F., Li, H., Shao, D. (2013): A New Indicator System for Chinese Social Stability Risk Assessment: Based on Governance of the Social Ecology System. - China Public Administration Review (2).

[29] Qu, X. E. (2017): Comprehensive evaluation of water resources carrying capacity in Shaanxi Province. - Journal of Arid Land Resources and Environment 31(2): 91-97.

[30] SGJ (2012): The Circular of the Ministry of Water Resources on Printing and Distributing the "Interim Measures for Social Stability Risk Assessment of Major Water Conservancy Projects". - (SGJ [2012] No. 474).

[31] Shi, Q., Liu, Y., Zuo, J., Pan, N., Ma, G. (2015): On the management of social risks of hydraulic infrastructure projects in china: a case study. - International Journal of Project Management 33(3): 483-496.

[32] Song, L. H. (1995): Social Risk Index System and Social Volatility Mechanism. SOCIOLOGICAL RESEARCH (6): 90-95.

[33] Sturk, R., Olsson, L., Johansson, J. (1996): Risk and decision analysis for large underground projects as applied to the Stockholm Ring Road Tunnels. - Tunneling and Underground Space Technology 11(2): 157-164.

[34] Sun, Y. (2011): Analysis on Large Social Problems in the Three Gorges Reservoir Area in Post -migration Period: Their Causes and the Suggestions for Their Solution. - China Soft Science (6): 24-33.

[35] Teng, M. M., Han, C. F., Liu, X. H. (2014): Index System for Social Impact Assessment of Large-Scale Infrastructure Projects in China. - China Population Resources and Environment 24(9): 170-176.

[36] Wang, W. S., Jin, J. L., Ding, J. (2009): A new approach to water resources system assessment: Set pair analysis method. - Science in China (Series E: Technological Sciences) 52(10): 3017-3023. 
[37] Wang, D., Zhang, Y. (2012): Operational Framework and Policy Suggestions for Social Stability Risk Assessment System of Large Engineering Projects. - Journal of Chinese Public Administration 12.

[38] Wang, B., Huang, D., Hua, J., Zhang, C. (2015): Research on the Social Stability Risk Assessment and Empirical Analysis of Hydraulic Engineering Construction. - China Population Resources and Environment 25(4): 149-154.

[39] Wang, J. L. (2017): The major project AHP-FCE method based on social stability risk assessment. - Social Scientist 2: 67-73.

[40] Wu, M. L. (2010): Questionnaire Statistical Analysis Practice-SPSS Operation and Application. - Chongqing: Chongqing University Press. 192-292.

[41] Wu, S. W., Qin, P., Gao, J. (2016): Application of Entropy Weight and Set Pair Analysis Theory to Risk Assessment of Dam Operation. - Journal of Yangtze River Scientific Research Institute 33(6): 36-40.

[42] Xiao, Q., Zhu, Z., Liu, H. (2016): Study on Non-intervention Online Assessment Model for Social Stability Risks of Large Engineering Projects. - Journal of Public Administration 9(1): 86-109,184.

[43] Xiao, Y. (2017): Social stability risk assessment of river engineering based on fuzzy variable theory. - Jiangsu Water Resources (10): 48-52.

[44] Yang, F. Y. (2012): On the Application of Social Combustion Theory in "Large Engineering Projects" - The Theoretical Foundation and Method Model of Social Stability Risk Assessment of Large Engineering Projects. - Journal of Zhejiang Provincial Party School 4.

[45] Yang, F. G., Liang, Y., Vijau, P. S. (2014): Debris flow hazard assessment using set pair analysis models: Take beichuan county as an example. - Journal of Mountain Science 11(4): 1015-1022.

[46] Yang, Y., Lv, X. (2017): Study on the Construction of Quantitative Index Mechanism of Social Stability Risk Assessment and Its Systematic System. - Industrial \& Science Tribune 16(21): 202-204.

[47] Yin, H., Jiang, R., Lin, P. (2018): Research on Social Stability Risk of PX Project. Journal of Engineering Studies 10(3): 276-287.

[48] Yu, W. X., Sun, B., Zhou, Y. (2016): Social Stability Risk Assessment and Control of LargeScale River Course Projects: Taking Huai River RH Project as an Example. Journal of Hohai University (Philosophy and Social Sciences) 18(4): 71-76, 91-92.

[49] Zhang, C. Z., Huang, D. C., Hua, J. (2013): Social Stability Risk Assessment for Large Hydraulic Projects. - Tsinghua University Press.

[50] Zhang, Y., Zhu, D. (2018): The Stakeholder Participation of Major Policy Social Stability Risk Assessment: Action Logic and Pattern Construction. - The Journal of Shanghai Administration Institute 19(5): 70-81.

[51] Zhao, K. Q. (2000): Set Pair Analysis and Its Preliminary Application. - Hangzhou: Zhejiang Science and Technology Press.

[52] Zhu, Z., Li, Z. X. (2014): Research on the Affectomg Factors of Public Participation Willingness in Social Stability Risk Evaluation. - Journal of Xi'an Jiaotong University (Social Sciences) 34(2): 49-55.

[53] Zhu, Z., Wang, Q., Guo, X. (2016): Research on Social Stability Risk Evaluation of Engineering Projects-Factor Analysis based on the Public "Risk - Benefit" Perception Perspective. - Journal of Xi'an Jiaotong University (Social Sciences) 36(3): 61-68. 